\title{
Effect of Co-Adsorbate and Hole Transporting Layer on the Photoinduced Charge Separation at the $\mathrm{TiO}_{2}-\mathrm{Phthalocyanine}$ Interface
}

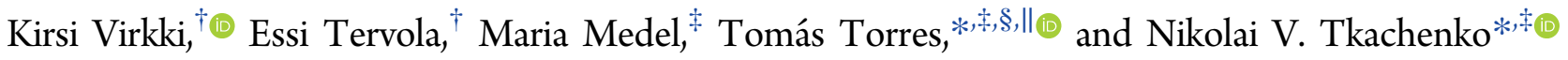 \\ ${ }^{\dagger}$ Laboratory of Chemistry and Bioengineering, Tampere University of Technology, P.O. Box 541, FI-33101 Tampere, Finland \\ ${ }^{\ddagger}$ Departamento de Química Orgánica, Universidad Autónoma de Madrid, Cantoblanco, E-28049 Madrid, Spain \\ ${ }^{\S}$ Institute for Advanced Research in Chemical Sciences (IAdChem), Universidad Autónoma de Madrid, 28049 Madrid, Spain \\ "IMDEA Nanociencia, C/Faraday, 9, Cantoblanco, 28049 Madrid, Spain
}

\section{Supporting Information}

\begin{abstract}
Understanding the primary processes of charge separation (CS) in solid-state dye-sensitized solar cells (DSSCs) and, in particular, analysis of the efficiency losses during these primary photoreactions is essential for designing new and efficient photosensitizers. Phthalocyanines (Pcs) are potentially interesting sensitizers having absorption in the red side of the optical spectrum and known to be efficient electron donors. However, the efficiencies of Pc-sensitized DSSCs are lower than that of the best DSSCs, which is commonly attributed to the aggregation tendency of Pcs. In this study, we employ ultrafast spectroscopy to discover why and how much does the aggregation affect the efficiency. The samples were prepared on a standard fluorine-doped tin oxide (FTO) substrates covered by a porous layer of $\mathrm{TiO}_{2}$ nanoparticles, functionalized by a Pc sensitizer and filled by a hole transporting material

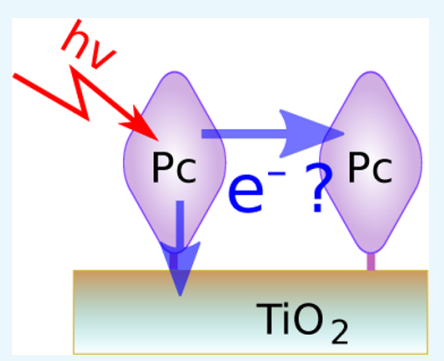
(Spiro-MeOTAD). The study demonstrates that the aggregation can be suppressed gradually by using co-adsorbates, such as chenodeoxycholic acid (CDCA) and oleic acid, but rather high concentrations of co-adsorbate is required. Gradually, a few times improvement of quantum efficiency was observed at sensitizer/co-adsorbate ratio Pc/CDCA $=1: 10$ and higher. The timeresolved spectroscopy studies were complemented by standard photocurrent measurements of the same sample structures, which also confirmed gradual increase in photon-to-current conversion efficiency on mixing Pc with CDCA.
\end{abstract}

\section{INTRODUCTION}

The performance and competitiveness of dye-sensitized solar cells (DSSCs) are improving constantly with the power conversion efficiency (PCE) exceeding $12 \%$ in laboratory conditions. ${ }^{1,2}$ However, the achieved efficiency is still behind the theoretical limit by a factor of 2 , and research efforts are refocused to examine and eliminate all pitfalls resulting in the efficiency loss. The final characterization of solar cells is done by measuring $I-V$ characteristics and calculating the maximum PCE or the external quantum efficiency. The PCE is the principal characteristic of the solar cells, but it depends on many internal processes and presents a cumulative effect of losses at different stages starting from the light caption and primary photoinduced charge separation (CS) to power losses due to resistivity of electrodes. ${ }^{3}$ Eventually, optimization of the DSSC should be done for all the processes involved and has to be based on the knowledge of all the individual steps of photonto-current conversion. The very first events of the photon conversion are extremely fast taking place in the femto- to picosecond time domain and were under active investigation for the past few decades using ultrafast optical and terahertz spectroscopy methods. ${ }^{4-8}$ The reactions of interest include light harvesting by sensitizers and electron injection to semiconductors in the picosecond time domain and following dye regeneration by electrolytes in the sub-nanosecond time domain in the case of liquid DSSCs. ${ }^{9,10}$

Solid-state DSSCs (ssDSSCs) are relatively new development in which the liquid electrolyte is replaced by a solid hole transporting material (HTM). ${ }^{11-13}$ This makes such devices more robust and attractive for large scale applications, though the best efficiencies achieved are roughly 2 times lower than that of traditional liquid DSSCs. ${ }^{14}$ Few specific challenges of ssDSSCs are selection of suitable small molecules for the HTM and pore filling by the material, ${ }^{15}$ which affect the conversion efficiency drastically and put restrictions on the thickness and porosity of the $\mathrm{TiO}_{2}$ layer. A common requirement for both liquid and ssDSSCs is design and syntheses of cost efficient sensitizers which have high absorption in the green-red part of the spectrum and close to unity quantum yield of CS at semiconductor-organic interfaces. ${ }^{12,16,17}$

Among a wide range of sensitizers tested in DSSC applications, porphyrin derivatives gained considerable attention recently, ${ }^{16,18-20}$ and porphyrin-based sensitizers were used to achieve the highest efficiencies in both types of DSSCs. ${ }^{1,14}$ The most efficient sensitizers are complex molecules with

Received: March 29, 2018

Accepted: April 26, 2018

Published: May 7, 2018 
specifically designed peripheral groups reducing interchromophore aggregation and implementing the so-called push-pull strategy when the sensitizer is complemented by electron donating and/or withdrawing groups accelerating electron injection to $\mathrm{TiO}_{2}$ from the photoexcited sensitizer. ${ }^{1,14,21,22}$ These are complex state-of-the-art compounds produced using multistep synthetic routes in very small amounts.

Although porphyrin derivatives are very versatile compounds for solar cell applications, they have a disadvantage of exhibiting relatively low absorption intensity in the green-red part of the spectrum. Therefore, another dye from the same group of tetrapyrrole macrocyclic compounds, phthalocyanine (Pc), has attracted attention because it is an equally good electron donor and has a strong absorption band in the red part of the spectrum. ${ }^{17}$ A number of Pc derivatives have been tested in DSSCs and demonstrated reasonably good efficiencies, ${ }^{23,24}$ though the final PCE was roughly 2 times lower than that of the best porphyrin and Ru-dye derivatives. Aggregation tendency of Pcs was considered to be the main reason for the efficiency loss. This stimulated the synthesis of Pcs with specifically designed bulky peripheral groups to reduce the aggregation, ${ }^{25,26}$ though this approach requires again multistep synthesis and thus gradually increases the cost of the compounds. Another possibility to solve the aggregation problem is to use coadsorbate compounds mixed with the photoactive Pcs during the sensitization process. ${ }^{27}$ An advantage of this approach is that it does not require synthesis of new and expensive compounds. This method was tested in a number of studies and has proven to increase the conversion efficiency but the efficiency gain was not as large as one could hope for.

The aims of the study reported herein are to use a reasonably inexpensive sensitizer, $\mathrm{Pc}$ derivative known as $\mathrm{TT} 1{ }^{23}$ to examine the primary photoreactions in ssDSSC model systems, to study the aggregation effect on the carrier generation, and to find out to which extent co-adsorbate may reduce the efficiency loss due to aggregation. To reduce the aggregation, the Pc was mixed with the widely used co-adsorbate, chenodeoxycholic acid (CDCA). ${ }^{28,29}$ In addition, oleic acid (OA), a well-known lipid molecule, was tested as a replacement for CDCA. The ssDSSC model samples were completed by infiltrating the layer of photosensitized $\mathrm{TiO}_{2}$ nanoparticles by the HTM, SpiroMeOTAD (Spiro). ${ }^{30,31}$ The primary photoreactions in the samples were studied by the ultrafast transient absorption (TA) spectroscopy technique also know as the pump-probe method. Both Pc and Spiro have distinct spectroscopy features of their transient states, cations and anions, ${ }^{32-34}$ which allow to establish reaction mechanisms and do quantitative evaluation of reaction rates and efficiencies. To compare the results of spectroscopy studies with "real life" use case of ssDSSCs, silver electrodes were deposited on top of the HTM and standard solar cell characterization was carried out for the same sample structures. For the comparison purpose, the quantum yields of photon-to-electron conversion were estimated. The comparison shows that CDCA can effectively reduce aggregation and even as simple Pc as TT1 can reach close to unity quantum yield of photocurrent generation.

\section{RESULTS AND DISCUSSION}

The chemical structure of zinc carboxyphthalocyanine (Pc) derivative used in this study is presented in Figure 1 together with those of two co-adsorbates, CDCA and OA. 2,2',7,7'Tetrakis(N,N-di-p-methoxyphenylamino)-9,9'-spirobifluorene (Spiro-MeOTAD or Spiro) was used as the HTM.
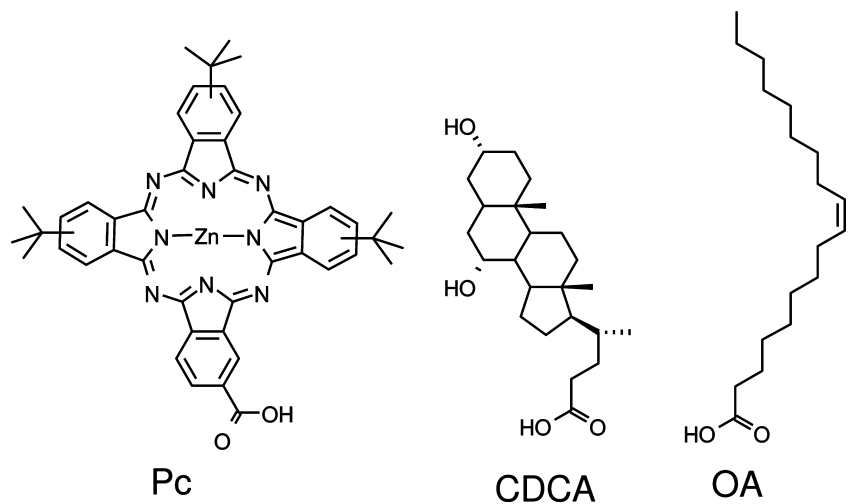

Figure 1. Compounds used to functionalize $\mathrm{TiO}_{2}$ nanoparticle films.

Samples were prepared on fluorine-doped tin oxide (FTO)coated glass substrates coated by a thin $\mathrm{TiO}_{2}$ compact layer, on top of which $\mathrm{TiO}_{2}$ mesoporous layers were prepared by screenprinting or spin-coated as described in Methods and Materials section below. The typical thickness of screen-printed layer was $2.5 \mu \mathrm{m}$ and of spin-coated $0.8 \mu \mathrm{m}$. Cross-section electron microscopy images of a few samples are shown in Supporting Information Figure S1.

2.1. Absorption Spectra. 2.1.1. Pc Aggregation on the $\mathrm{TiO}_{2}$ Surface. Absorption spectra of Pcs change significantly upon aggregation. This change can be used for monitoring the degree of aggregation. The absorption spectrum of the Pc in a good solvent, ethanol (EtOH), at a low concentration (roughly $0.8 \mu \mathrm{M}$ ) is shown in Supporting Information Figure S2. The spectrum has relatively narrow band at $677 \mathrm{~nm}$, the Q-band, and a shoulder in the $600-650 \mathrm{~nm}$ range. However, to deposit the $\mathrm{Pc}$ onto $\mathrm{TiO}_{2}$, the concentration of $\mathrm{Pc}$ must be much higher. Furthermore, it was noted previously that for similar Pcs, a 1:1 (vol/vol) mixture of tert-butanol and $\mathrm{MeCN}$ is a better solvent for self-assembled monolayer (SAM) deposition on $\mathrm{ZnO}^{35}$ It turned out that the same mixture allows deposition of stable SAMs on $\mathrm{TiO}_{2}$. Absorption spectra of the $\mathrm{Pc}$ in this solvent at a concentration close to what was used for the SAM depositions (roughly $50 \mu \mathrm{M}$ ) are shown in Figure S3 in the Supporting Information. There is noticeable aggregation of Pc in this solution, which also can be reduced by adding a co-adsorbate such as CDCA. The absorption spectra for the Pc/CDCA mixtures with different Pc/CDCA ratios can also be found in Figure S3.

Absorption spectra of a series of Pc SAMs on $\mathrm{TiO}_{2}$ with varying relative concentrations of the co-adsorbates are presented in Figure 2. As a rough approximation, the absorption spectra in the Q-band area $(580-720 \mathrm{~nm})$ can be presented as superposition of two bands, a "blue" band with maximum close to $630 \mathrm{~nm}$ and a "red" band with maximum in the $680-690 \mathrm{~nm}$ range. A clear sign of aggregation is high relative intensity of the blue band and broadening of the red band. These are typical features of Pc aggregates, and sharp rise of the blue band can be tentatively attributed to H-type aggregation or formation of face-to-face aggregates. ${ }^{36}$ The spectrum of the sample without the co-adsorbate is the broadest and it has the highest relative intensity at the blue band, which can be considered as the highest degree of aggregation in this series.

As a measure of aggregation, the relative intensities of the blue band with respect to the red band were calculated by decomposing the spectrum on two Gaussian bands and 


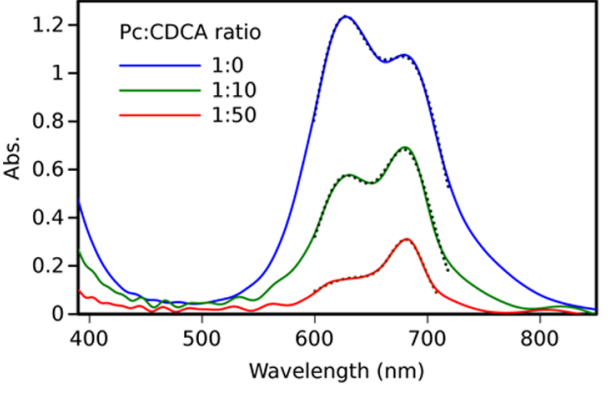

(a)

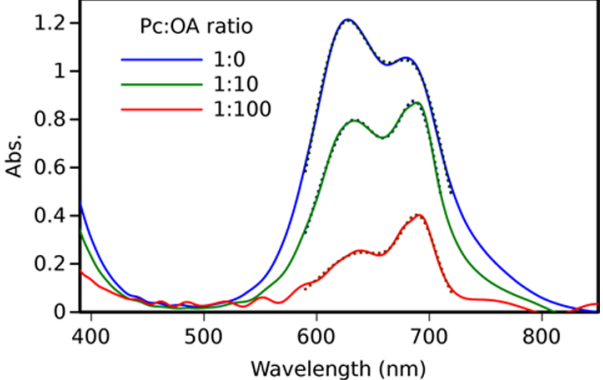

(b)

Figure 2. Absorption spectra of $\mathrm{Pc} \mathrm{SAMs} \mathrm{on} \mathrm{TiO}_{2}$ with different relative concentrations of (a) CDCA and (b) OA. Solid lines are measured spectra after subtracting spectra of $\mathrm{TiO}_{2}$-covered substrates and dotted lines are two band approximations of the Q-band area.

calculating the ratio of the band intensities (see Table $S 1$ in the Supporting Information). According to this aggregation degree estimation, CDCA reduces the aggregation more efficiently than OA. The ratio decreases from 1.18 for the pure Pc SAM to 0.83 and 0.5 for relative CDCA concentrations of 10 and 50, respectively. However, for OA it decreases to only 1.0 and 0.65 for relative OA concentrations of 10 and 100, respectively. It has to be noted that the lipid structure of the OA molecule might take less space in the SAM than the steroid base CDCA, thus resulting in higher surface density of $\mathrm{Pc}$ in $\mathrm{OA}$ environment than in CDCA.

Furthermore, the surface binding rate of $\mathrm{Pc}, \mathrm{CDCA}$, and $\mathrm{OA}$ may differ and the ratio of molecules $\mathrm{Pc} / \mathrm{CDCA}$ or Pc/OA on the $\mathrm{TiO}_{2}$ surface may differ from the corresponding ratios in the sensitization solution used to deposit SAM. Estimation of the surface density is a complicated task in this case, but one can compare decrease of absorption intensities at increased coadsorbate concentrations and make some qualitative conclusions. This analysis is presented in Supporting Information (Table S1, Figure S6, and corresponding comments), and it suggests that (1) co-adsorbate to Pc molecular ratio on the $\mathrm{TiO}_{2}$ surface is few times lower than that in the layer deposition solution (relative proportion Pc is few times higher in solid samples), which is probably due to higher binding rate of Pc compared to CDCA and OA, and (2) at the same Pc to coadsorbate molar ratio, the average surface density of the $\mathrm{Pc}$ is higher in the OA samples than in the CDCA samples, resulting in a higher absorption for the Pc/OA samples compared to the Pc/CDCA samples. Because accurate estimation of the Pc/coadsorbate ratio on the $\mathrm{TiO}_{2}$ surface was not possible at this stage, the samples will be distinguished by the molar ratio in the sensitization solution in this study, meaning that, for example, the ratio 1:10 refers to the ratio in the solution used to prepare the sample. This is justified by reasonably proportional decrease of Pc density with increase of the co-adsorbate concentration in the solution as presented in Supporting Information Figure S6.

Even at the highest relative co-adsorbate concentrations shown in Figure 2, the Pc spectra are still not a perfect match with the Pc spectrum in a good solvent at a low concentration (Figure S2). This can be interpreted as some remaining aggregation. Another reason for the difference is the completely different environment in the SAMs compared to a solution. Higher concentrations of the co-adsorbates were tested but the absorption of such samples was lower with the spectrum shape remaining essentially the same.

Samples with OA co-adsorbate were observed to degrade faster than the CDCA-containing samples. In particular at $\mathrm{Pc} /$ $\mathrm{OA}=1: 100$, the sample became colorless after 2 days when kept in the dark. On the contrary, practically no detectable degradation was noticed for the Pc/CDCA = 1:50 sample after a week of storage. Degradation was lower for lower OA concentration, for example at $\mathrm{Pc} / \mathrm{OA}=1: 10$ the degradation was less than $20 \%$ (of absorption intensity) after a few days.

2.1.2. Effect of Spiro on PC Absorption. Addition of the HTM had also a strong effect on the steady-state absorption spectra of the samples, as illustrated in Figure 3. In all samples,

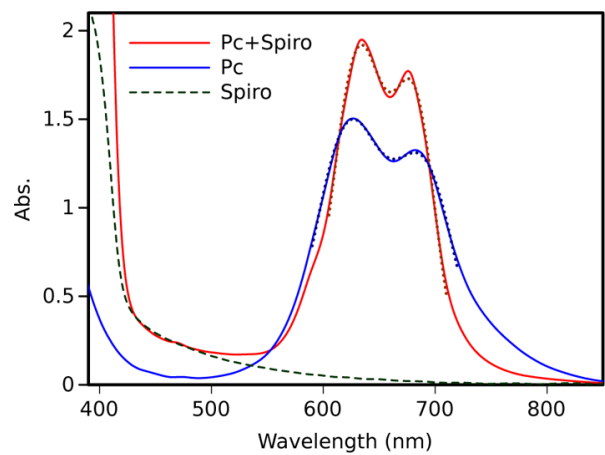

Figure 3. Absorption spectra of Pc SAMs before (blue) and after (red) deposition of Spiro hole transporting layer and absorption spectrum of a reference Spiro sample (green dashed line). Solid lines are measured spectra (after subtracting spectra of $\mathrm{TiO}_{2}$-covered substrates) and dotted lines are two band approximations of the Q-band area.

the absorption intensity increased slightly in the Q-band region and the spectra became slightly narrower after the deposition of Spiro. It can be noticed that Spiro has negligible absorption in the green-red part of the spectrum. Its absorption dominates in the ultraviolet (UV)-blue region, and it is seen as a sharp rise at wavelengths shorter than $420 \mathrm{~nm}$ in Figure 3. Therefore, the absorption in the 550-750 nm region is solely due to the Pc. For the sample shown in Figure 3, the width of the band at $620-630 \mathrm{~nm}$ decreases from 30 to $23 \mathrm{~nm}$ and for the band at $680-690 \mathrm{~nm}$ from 27 to $19 \mathrm{~nm}$ on addition of the Spiro layer, which is typically interpreted as lower aggregation degree. However, the band ratio remains virtually the same, 1.23 and 1.25 , respectively, which leads to a conclusion that relative proportion of $\mathrm{H}$-type aggregates is the same. If the ratio is taken as a measure of aggregation degree, one may conclude that the type of aggregation does not change, but the aggregates are more homogeneous after Spiro deposition, which results in the band narrowing. Similar changes were observed for other samples, see Figures S4, S5 and Table S1 in the Supporting Information. Importantly, no detectable degradation was observed for any of the samples covered with the Spiro hole 


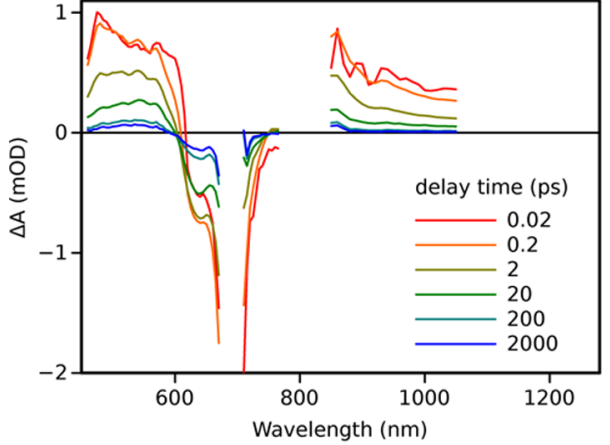

(a)

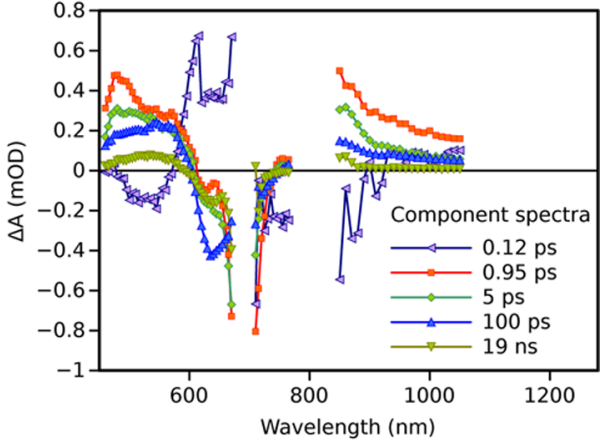

(b)

Figure 4. (a) TA spectra and (b) decay component spectra for the Pc/CDCA $=1: 50$ sample. Excitation wavelength was $695 \mathrm{~nm}$.

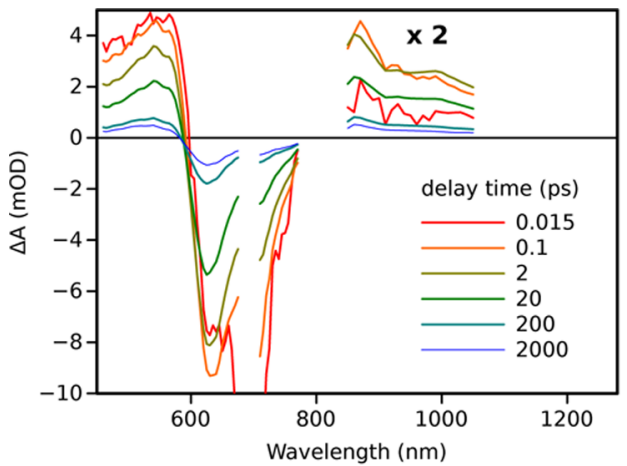

(a)

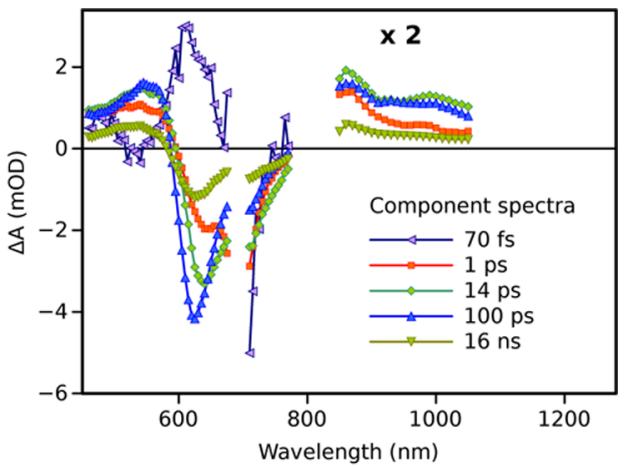

(b)

Figure 5. (a) Time-resolved TA spectra and (b) decay component spectra for the Pc sample without a co-adsorbate. Excitation wavelength was 695 $\mathrm{nm}$. The response in the NIR $(840-1060 \mathrm{~nm})$ is multiplied by 2 for clarity.

transporting layer within a few weeks, regardless of which coadsorbate was used.

These changes in the absorption spectra upon addition of the Spiro layer can be rationalized assuming that Spiro has a tendency to fill the space between the Pc molecules, resulting in weaker inter-Pc interactions and thus a lower degree of aggregation. This phenomenon is desired as it may also improve the efficiency of the hole collection from the Pc monolayer after electron injection into $\mathrm{TiO}_{2}$. It also may result in an efficient electron or hole transfer at the PclSpiro interface, as was reported previously, ${ }^{35}$ and will be discussed below.

As a summary of the examination of the steady-state absorption spectra, the Pc/CDCA $=1: 50$ sample is taken as the model example of a virtually nonaggregated sample, although the absorption spectrum of the sample is not a perfect match with the absorption spectrum of this $\mathrm{Pc}$ in a good solvent (Figure S2 in the Supporting Information).

2.2. TA Responses of $\mathrm{TiO}_{2}-\mathrm{Pc}$ Samples. First, the samples without the Spiro layer were studied. The timeresolved TA spectra of the least aggregated sample, Pc/CDCA $=1: 50$, are shown in Figure $4 \mathrm{a}$ at a few selected delay times. The spectra were corrected for the group velocity dispersion and the instrument response function (roughly $0.1 \mathrm{ps}$ ), which is essential for a short delay times and fast decay components. Therefore, the spectrum at 0.02 ps delay time can be considered as an "ideal" spectrum formed instantly after the excitation and can be taken as the spectrum of the singlet excited state, $\mathrm{Pc}^{*}$. It has a relatively flat absorption in the 470$610 \mathrm{~nm}$ range and a broad absorption at $>850 \mathrm{~nm}$ that slowly decreases toward the longer wavelengths. At later delay times, the spectrum is transformed to show a broad absorption band around $540 \mathrm{~nm}$ and a relatively sharp band near $860 \mathrm{~nm}$. Both of these features are typical of the Pc cation, ${ }^{32,35,37,38}$ which is in agreement with the expected electron injection from the excited $\mathrm{Pc}^{*}$ into $\mathrm{TiO}_{2}$.

In this case, the expected sequence of reactions following photoexcitation of $\mathrm{Pc}$ is

$$
\mathrm{TiO}_{2}\left|\mathrm{Pc}^{*} \stackrel{\tau_{\text {inj }}}{\rightarrow} \mathrm{TiO}_{2}{ }^{-}\right| \mathrm{Pc}^{+} \stackrel{\tau_{\text {cr }}}{\rightarrow} \mathrm{TiO}_{2} \mid \mathrm{Pc}
$$

where $\tau_{\text {inj }}$ is the electron injection time constant and $\tau_{\text {cr }}$ is the time constant of the charge recombination $(\mathrm{CR})$ at the $\mathrm{TiO}_{2} \mid \mathrm{Pc}$ interface. Despite this rather simple reaction chain, at least fiveexponential fit had to be used to obtain a reasonably good approximation of the TA decays in the 460-1050 nm wavelength range (Figure $4 \mathrm{~b}$ ). However, one can notice that there is no significant difference in the component spectra shapes in a wide time domain covering several time constants of the fit (5 ps, 100 ps, and $19 \mathrm{~ns}$ ). This indicates inhomogeneity in the sample which leads to essentially "nonexponential" decay kinetics of the $\mathrm{CR}$ at the $\mathrm{TiO}_{2} \mid \mathrm{Pc}$ interface. Similar nonexponential decays were reported for virtually all similar systems. ${ }^{4-6,9}$ On a qualitative level, the fast component, $0.12 \mathrm{ps}$, has features indicating formation of the bands at 540 and 860 $\mathrm{nm}$ and can be attributed to the electron injection from Pc* to $\mathrm{TiO}_{2}$ with $\tau_{\text {inj }}=0.12 \mathrm{ps}$. The following component, $0.95 \mathrm{ps}$, results in the formation of a better pronounced cation spectrum (Figure $4 \mathrm{a}$, spectrum at 2 ps delay time). It is a mixture of competing electron injection and nonradiative excited state relaxation reactions most probably. After that the spectrum shape virtually does not change and this decay can be attributed 
to the $\mathrm{CR}$ at the semiconductor-sensitizer interface which is known to be essentially nonexponential ${ }^{7,9}$ and in this case is spread in the time interval from few picoseconds to tens of nanoseconds.

The corresponding time-resolved and decay component spectra for the sample without any co-adsorbate are shown in Figure 5. Although the TA response of the sample seems to be similar to that with CDCA, there are a few essential differences. First of all, it is even more difficult to find a delay time at which the singlet excited state of the Pc would be well-resolved in the sample without a co-adsorbate. The shortest time constant obtained from the fit, $70 \mathrm{fs}$, is shorter than the time resolution of the instrument (roughly $100 \mathrm{fs}$ ), and although it can be assigned to the excited state relaxation, the corrected spectrum generated for a very short delay time ( $0.015 \mathrm{ps,} \mathrm{in} \mathrm{Figure} 5 \mathrm{a})$ has features deviating gradually from that of the singlet excited state in the visible part of the spectrum, and it has low and "noisy" intensity in the near-infrared (NIR) part of the spectrum. This mismatch between the visible and NIR parts is most probably due to the limited accuracy of the group velocity compensation but not to any real phenomenon. Second, one can notice a relatively high absorption in the 950$1000 \mathrm{~nm}$ range for the aggregated sample and even a broad band at these wavelengths in the decay components with time constants 1 and 14 ps. The Pc anion is known to have an absorption band in this wavelength range, ${ }^{33,39-41}$ though the band is broader than typically observed for Pc anions, which can be attributed to rather random aggregation of Pcs on the $\mathrm{TiO}_{2}$ surface. Appearance of this band can be interpreted in favor of a CS reaction in the excited aggregates, or intraaggregate $\mathrm{CS}$, with a time constant $\tau_{\text {agg }}$

$$
\mathrm{Pc}^{*}-\mathrm{Pc} \stackrel{\tau_{\mathrm{agg}}}{\rightarrow} \mathrm{Pc}^{+}-\mathrm{Pc}^{-}
$$

Although the mechanism of CS may be more complex and may involve formation of an intermolecular exciplex prior the complete CS, as was reported for Pc-fullerene dyads with strong electronic coupling. ${ }^{42}$ In any case, this is the process competing with the electron injection into $\mathrm{TiO}_{2}$ from the initially generated excited state, $\mathrm{Pc}^{*}$, and it reduces the lifetime of the singlet excited state compared to that of the nonaggregated sample $(\mathrm{Pc} / \mathrm{CDCA}=1: 50)$. Within this simplified model, the observed singlet state relaxation time constant is $\tau_{\mathrm{s}}=\left(\tau_{\mathrm{inj}}{ }^{-1}+\tau_{\mathrm{agg}}{ }^{-1}\right)^{-1} \approx 70 \mathrm{fs}$, and $\tau_{\mathrm{agg}} \approx 0.13 \mathrm{ps}$, or roughly equal to $\tau_{\text {inj; }}$.

The TA response of the Pc/CDCA $=1: 10$ sample takes an intermediate position between responses of the two samples discussed above (see Figure S7 in the Supporting Information).

The time-resolved spectra of the $\mathrm{Pc} / \mathrm{OA}=1: 10$ sample are presented in Figure 6. The response is very similar to that of the sample with CDCA as the co-adsorbate, though the spectra at longer delay time are slightly stronger, for example, at 2000 ps, indicating that relative yield of the long-lived $\mathrm{Pc}^{+}$is marginally higher in the sample with OA. However, the yield of the long-lived $\mathrm{Pc}^{+}$is small in both cases being not more than $20 \%$ relative to that of the Pc/CDCA $=1: 50$ sample.

Because of the rapid degradation of the Pc/OA samples, especially at high OA concentrations, reliable spectroscopic data were not obtained.

The primary CS in both series of samples with CDCA and OA was at the limit of the time resolution of the instrument used, 100 fs. Within this time resolution limit, the two coadsorbates have the same effect on the relaxation of the singlet excited state, $\mathrm{Pc}^{*}$. The two main processes contributing to the

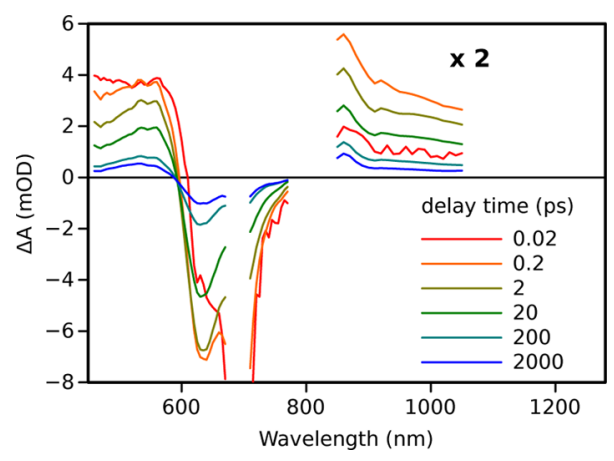

Figure 6. Time-resolved TA spectra of $\mathrm{Pc} / \mathrm{OA}=1: 10$ sample. The response in the NIR $(840-1060 \mathrm{~nm})$ is multiplied by 2 for clarity.

Pc* relaxation are the electron injection into $\mathrm{TiO}_{2}$ and intraaggregate CS. This leads to the disappearance of the Pc singlet excited state within the time interval close to $100 \mathrm{fs}$. The samples are quite heterogeneous, however, and the $\mathrm{Pc}^{*}$ relaxation is not exponential. A "tail" of the singlet relaxation is extended to the picosecond time domain. We cannot exclude nonradiative intra-aggregate relaxation, but its contribution does not seem to be high and it is difficult to quantify.

The wavelength range of the most different decay profiles for the studied samples is $900-1050 \mathrm{~nm}$. Figure 7 a presents decays at $990 \mathrm{~nm}$ as an example. Two intermediate states have the main contribution to the TA at this wavelength: the singlet excited state, $\mathrm{Pc}^{*}$, and the $\mathrm{Pc}$ anion, $\mathrm{Pc}^{-}$. Being the least aggregated sample, the Pc/CDCA $=1: 50$ sample shows the fastest decay at this wavelength because there is no intraaggregate $\mathrm{CS}$ and thus no $\mathrm{Pc}^{-}$formed. Respectively, the sample with no co-adsorbate shows the strongest response at the middle delay times, roughly $1-20 \mathrm{ps}$, being the most aggregated and thus the most efficient in generating $\mathrm{Pc}^{-}$. However, the final relaxations of the Pc/CDCA $=1: 10$ and coadsorbate-free samples are roughly the same, indicating that the relaxation of $\mathrm{Pc}^{-}$is not sensitive to the concentration of CDCA.

The OA co-adsorbate is less efficient in reducing aggregation effect, according to the relative intensity of the TA at $990 \mathrm{~nm}$ in the 1-20 ps delay time interval. The decay of the sample with OA co-adsorbate is slightly slower than that with CDCA; however, the difference is rather minor.

Another important wavelength is $860 \mathrm{~nm}$, because this is the wavelength of maximum absorption of the $\mathrm{Pc}$ cation, $\mathrm{Pc}^{+}$. The decays at $860 \mathrm{~nm}$ are presented in Figure $7 \mathrm{~b}$ for the same set of samples. Unfortunately, the singlet state has also relatively high absorption at this wavelength. Therefore, the transition $\mathrm{Pc}^{*} \rightarrow$ $\mathrm{Pc}^{+}$has virtually no effect on the absorption. Another intermediate state which has a significant contribution to the absorption at this wavelength is the $\mathrm{Pc}$ anion, $\mathrm{Pc}^{-}$. The anion absorption band is at $990 \mathrm{~nm}$, but at shorter wavelengths it has a flat absorption with intensity at $860 \mathrm{~nm}$ close to half of that at $990 \mathrm{~nm}$ (see below).

Assuming that the Pc/CDCA $=1: 50$ sample is virtually nonaggregated, the decay at $860 \mathrm{~nm}$ can be used to monitor the $\mathrm{CR}$ process at the semiconductor-sensitizer interface, eq 1. Then, the first conclusion is that the CR is essentially a nonexponential process, as can be expected. The TA intensity drops by roughly $50 \%$ during the first 3 ps, indicating that $50 \%$ of the $\mathrm{Pc}^{+}$have recombined. Roughly half of the left cations relax in the following 10 ps. For the remaining part, recombination is shifted to hundreds of picoseconds, and roughly $10 \%$ of the Pc cations have a lifetime extended to the 


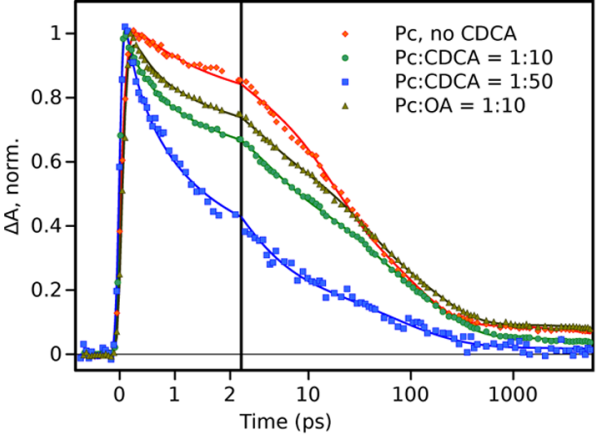

(a)

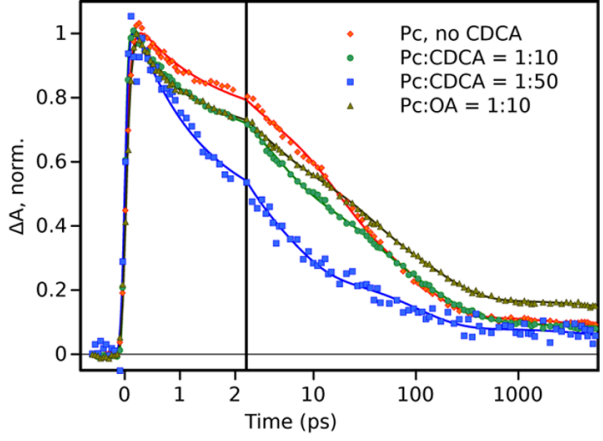

(b)

Figure 7. Normalized TA decays at (a) 990 and (b) $860 \mathrm{~nm}$ for four samples: Pc SAM without a co-adsorbate, two different relative concentrations of CDCA, $1: 10$ and 1:50, and OA at 1:10.

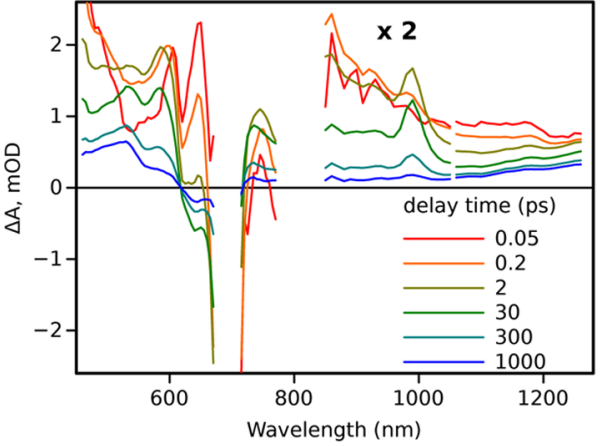

(a)

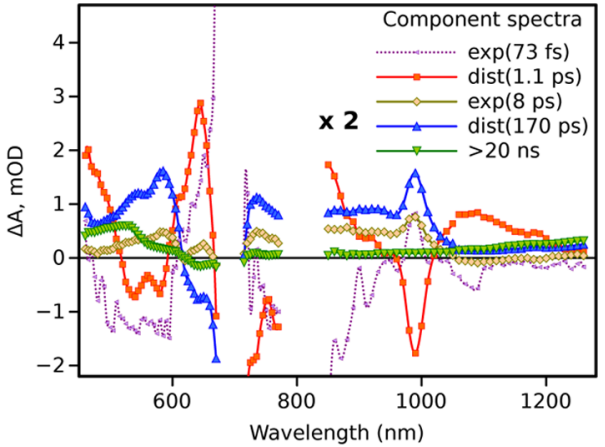

(b)

Figure 8. (a) Time-resolved TA spectra and (b) decay component spectra of the sample with Pc/CDCA = 1:50 covered by Spiro. The fit model combined exponential distributed decay functions ${ }^{35}$ denoted as $\exp (\tau)$ and $\operatorname{dist}\left(\tau_{\text {aver }}\right)$, respectively. Excitation wavelength was $695 \mathrm{~nm}$. The NIR response $(840-1260 \mathrm{~nm})$ is multiplied by 2 .

nanosecond time domain. This is rather fast CR. For example, the longest reported half times are $>1$ ns for porphyrin sensitizer, ${ }^{9,43}$ and much more than $1 \mathrm{~ns}$ for Ru-dyes. ${ }^{10}$ Rather fast $\mathrm{CR}$ at the $\mathrm{TiO}_{2} \mid \mathrm{Pc}$ interface is surprising and undesired result. It was noticed that the electron injection from sensitizer into $\mathrm{TiO}_{2}$ takes place in two steps. ${ }^{7}$ The first step is an electrostatically coupled electron-cation complex is formed, and then, the electron leaves the surface and becomes a "free" carrier in the conduction band of $\mathrm{TiO}_{2}$. A possible explanation of a faster recombination is that the electron-cation complex is more stable for Pc than for porphyrin and Ru-dye sensitizers studied previously. This would result in a competition between the CR of the complex and the electron promotion into the $\mathrm{TiO}_{2}$ bulk, which leaves a long-lived cation on the surface. In the case of the $\mathrm{TiO}_{2} \mid \mathrm{Pc}$ interface, the competition is shifted in favor of the first process, surface complex recombination, which is definitely an undesired process.

For the samples without co-adsorbates or relatively low concentration of co-adsorbates (e.g. 1:10), the cation band at $860 \mathrm{~nm}$ cannot be used as an indicator of the CS efficiency at the $\mathrm{TiO}_{2} \mid \mathrm{Pc}$ interface, because the electron injection is competing with CS (eq 2) in the Pc aggregates. The reason for the slower decay of these samples is the slower relaxation of the intra-aggregate charge separated state compared to the CR at the $\mathrm{TiO}_{2} \mid \mathrm{Pc}$ interface.

One can presume that the $\mathrm{Pc}^{-}$formed as the result of intraaggregate CS may later inject an electron into $\mathrm{TiO}_{2}$ and thus contribute to the CS at the organic-semiconductor interface through a two-step process

$$
\begin{aligned}
& \mathrm{TiO}_{2} \mid\left(\mathrm{Pc}^{*}-\mathrm{Pc}\right) \stackrel{\tau_{\mathrm{agg}}}{\rightarrow} \mathrm{TiO}_{2} \mid\left(\mathrm{Pc}^{+}-\mathrm{Pc}^{-}\right) \\
& \stackrel{\tau_{\mathrm{el}}}{\rightarrow} \mathrm{TiO}_{2}^{-} \mid\left(\mathrm{Pc}^{+}-\mathrm{Pc}\right)
\end{aligned}
$$

An indication of this process is a slower decay of TA at 860 $\mathrm{nm}\left(\mathrm{Pc}^{+}\right.$indicator) compared to that at $990 \mathrm{~nm}$ (indicator of $\mathrm{Pc}^{-}$) for the co-adsorbate-free sample. However, we did not come up with a method of quantitative separation of these two processes. In a qualitative level, the remaining absorption at 860 $\mathrm{nm}$ (indicator of $\mathrm{Pc}^{+}$) is not higher than that of the least aggregated sample with still measurable absorption at $990 \mathrm{~nm}$ (indicator of $\mathrm{Pc}^{-}$). Therefore, the efficiency of reactions in eq 3 is low for all samples.

2.3. Samples with Spiro Overlayer: Effect of the Hole Transporting Layer. The effect of the HTM, Spiro, on the photoinduced $\mathrm{CS}$ at the organic-semiconductor interface of the least aggregated sample is very similar to that reported for aggregation protected Pcs on $\mathrm{ZnO}$ nanorods. ${ }^{35}$ The timeresolved TA spectra of the $\mathrm{Pc} / \mathrm{CDCA}=1: 50$ sample covered by the Spiro layer are shown in Figure $8 \mathrm{a}$, and the global fit results using the model combining exponential and distributed decay (see ref 35 for details) are presented in Figure 8b, respectively. Comparing to the sample without the HTM layer, the most obvious difference in the TA response is a rather sharp band at $990 \mathrm{~nm}$ which forms with a time constant close to $1 \mathrm{ps}$ and decays with a time constant close to 170 ps (see Figure S7 in the Supporting Information). This band can be attributed to the anion $\mathrm{Pc}^{-35,39,40}$ Another characteristic feature of the anion 
is the band close to $590 \mathrm{~nm}$, which is most clearly seen in the 170 ps component.

The first qualitative conclusion which can be made comparing TA measurements of the Pc/CDCA $=1: 50$ sample with and without Spiro, presented in Figures 8 and 4, respectively, is that Spiro not only penetrates through the whole $2 \mu \mathrm{m}$ thick $\mathrm{TiO}_{2}$ layer, but it is in contact with most Pc sensitizers. This conclusion becomes evident after comparing time-resolved spectra at long delay time. The spectra of the sample with Spiro holds mainly the features of the Spiro cation, the band $590 \mathrm{~nm}$ and very weak and featureless absorption in the $850-1100 \mathrm{~nm}$ range, and only a minor bleaching at $650 \mathrm{~nm}$ which may arise from minor population of Pc not interacting with Spiro. Whereas features of the Spiro-free sample is a band at $860 \mathrm{~nm}$ and relatively strong bleaching at $650 \mathrm{~nm}$ compared to the broad and featureless induced absorption band at 500$600 \mathrm{~nm}$.

Assuming that Pcs are nonaggregated in the sample with Spiro and the intra-aggregate CS can be excluded, the only feasible reaction to generate $\mathrm{Pc}^{-}$is the $\mathrm{CS}$ at interface between Pc and Spiro

$$
\mathrm{Pc}^{*} \mid \text { Spiro } \stackrel{\tau_{\mathrm{sp}}}{\rightarrow} \mathrm{Pc}^{-} \mid \text {Spiro }^{+}
$$

where $\tau_{\mathrm{sp}}$ is the time constant for the hole transfer from the excited Pc to Spiro. The spectra at long delay times (e.g. at 1000 ps, Figure 8a) and the spectrum of the long-lived component ( $>20 \mathrm{~ns}$, Figure $8 \mathrm{~b})$, respectively, can be attributed to the Spiro cation. ${ }^{11,34,35,40}$ It has a band at $530 \mathrm{~nm}$ and a broad absorption in the IR region which is observed as a slowly rising absorption toward the longer wavelengths starting from $1000 \mathrm{~nm}$. Therefore, relaxation of the $\mathrm{Pc}^{-} \mathrm{can}$ be attributed to the electron injection into $\mathrm{TiO}_{2}$

$$
\mathrm{TiO}_{2}\left|\mathrm{Pc}^{-}\right| \text {Spiro } \stackrel{+}{+} \stackrel{\tau_{\text {et }}}{\rightarrow} \mathrm{TiO}_{2}{ }^{-} \mid \mathrm{PclSpiro}{ }^{+}
$$

where $\tau_{\text {et }}$ is the time constant of the electron transfer from $\mathrm{Pc}^{-}$ into $\mathrm{TiO}_{2}$.

In addition to the reaction sequence depicted by eqs 4 and 5 , the long-distance CS state can be obtained by a competing process. Here, the electron is first injected from the $\mathrm{Pc}^{*}$ into $\mathrm{TiO}_{2}$, followed by the hole transfer from the $\mathrm{Pc}^{+}$to the Spiro

$$
\mathrm{TiO}_{2}|\mathrm{Pc} *| \text { Spiro } \stackrel{\tau_{\text {inj }}}{\rightarrow} \mathrm{TiO}_{2}{ }^{-}\left|\mathrm{Pc}^{+}\right| \text {Spiro } \stackrel{\tau_{\text {ht }}}{\rightarrow} \mathrm{TiO}_{2}{ }^{-} \mid \mathrm{Pcl} \text { piroo }{ }^{+}
$$

where $\tau_{\mathrm{ht}}$ is the time constant of the hole transfer from $\mathrm{Pc}^{+}$to Spiro.

The electron injection time constant, $\tau_{\text {inj, in the sample }}$ without Spiro is roughly $0.12 \mathrm{ps}$, and it competes with the CS at Pc*|Spiro having time constant of $\approx 1$ ps. In a homogeneous system, a process with a few times longer time constant would be very inefficient. The $\mathrm{Pc}$ monolayer on $\mathrm{TiO}_{2}$ is, however, not homogeneous. Even more importantly, noticing a gradual change in the absorption spectra of the samples with and without Spiro, one can expect that Spiro changes the packing of the Pc molecules on the semiconductor surface. More specifically, it is likely that Spiro molecules tend to penetrate between the Pcs, thus reducing inter-Pc interactions and enforcing an upright orientation of the Pc molecules on the $\mathrm{TiO}_{2}$ surface. The latter has an effect of increased distance from the Pc core to the surface and will result in a slower electron injection into $\mathrm{TiO}_{2}$.

The reaction sequence in eq 6 would result in a relatively sharp transient band at $860 \mathrm{~nm}$ and a broad band around 540 $\mathrm{nm}$ corresponding to $\mathrm{Pc}^{+}$, which would later transform into a broad band around $530 \mathrm{~nm}$ and a broad absorption in the NIR region. The observed $\mathrm{TA}$ response of the $\mathrm{TiO}_{2} \mid \mathrm{Pc} / \mathrm{CDCA}$ Spiro sample has no such features. Furthermore, the singlet excited state features for the Pc can be noticed in the timeresolved spectra at delay times as long as 0.2 ps as sub-band structures in the 590-650 $\mathrm{nm}$ region. Therefore, the main relaxation pathway of the excited state is the sequence of reactions 4 and 5, with average reaction time constants $\tau_{\mathrm{sp}} \approx 1$ ps and $\tau_{\text {et }} \approx 170$ ps.

The TA responses of the most aggregated sample, Pc layer without the co-adsorbate, are shown in Figure 9. The essential

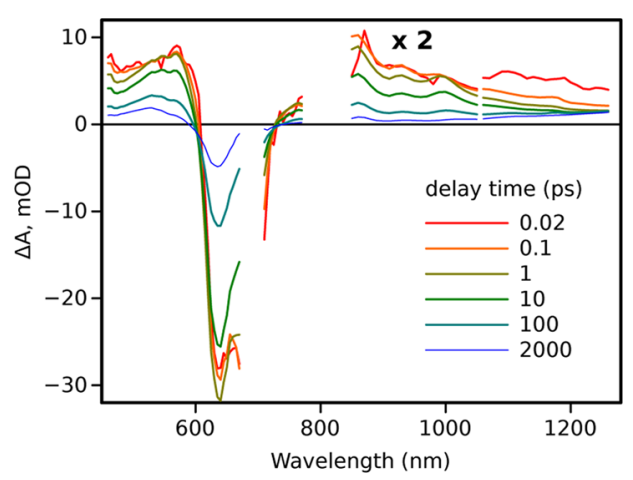

Figure 9. Time-resolved TA spectra of the $\mathrm{TiO}_{2} \mid \mathrm{Pcl}$ Spiro sample. The NIR response $(840-1260 \mathrm{~nm})$ is multiplied by 2 .

difference with the nonaggregated sample at short delay times is the virtually nonresolved singlet excited state of the Pc. Overall, the spectra of pure Pc samples with (Figure 9) and without (Figure 5a) Spiro are very similar at least within the first 100 ps relaxation time, though the $\mathrm{Pc}^{-}$band is more pronounced in the sample with Spiro top layer. This suggests that intraaggregate $\mathrm{CS}$ is the dominating reaction pathway. At longer delay times, a broad NIR band attributed to Spiro ${ }^{+}$becomes visible, though the intensity of the band is much lower for the sample without a co-adsorbate. The global exponential fitting of the TA data is presented in Figure S9 in the Supporting Information. The fitting results suggest that the intra-aggregate CS takes place with a time constant $\tau_{\text {agg }} \approx 0.16 \mathrm{ps}$, and the following relaxation of the $\mathrm{Pc}^{-}$takes place in the time interval 1-300 ps. These time constants are slightly longer than in the case of the sample without Spiro, but the difference is rather marginal.

Comparison of the TA spectra in Figures 8 and 9 indicates that at long delay times the yield of the long-distance CS state, $\mathrm{TiO}_{2}{ }^{-} \mid \mathrm{Pcl}$ Spiro ${ }^{+}$, is higher in the $\mathrm{Pc} / \mathrm{CDCA}=1: 50$ sample, which is seen as higher relative intensities at 530 and $1250 \mathrm{~nm}$. However, there are probably still some losses in the longdistance CS yield at few hundred picosecond delay time even in the 1:50 sample, because the component with the 170 ps time constant (Figure $8 \mathrm{~b}$ ) has an IR tail with intensity rising toward longer wavelengths, though this IR tail is smaller in intensity than that of the longest lived component ( $>20 \mathrm{~ns}$ in Figure $8 \mathrm{~b}$ ). This means that some of the Pc anions may relax as the result of $\mathrm{CR}$ at the $\mathrm{Pc}^{-} \mid$Spiro ${ }^{+}$interface, instead of donating an electron to $\mathrm{TiO}_{2}$. The effect of this relaxation on the solar cell performance depends on time needed for the hole to reach the cathode, if holes leave the HTM faster than the relaxation constant, the relaxation will have no considerable effect on the cell performance. 
The TA responses for the samples with Pc/CDCA $=1: 10$ and $\mathrm{Pc} / \mathrm{OA}=1: 10$ are shown in the Supporting Information (Figures S10-S13). The responses take intermediate positions between the sample with high concentration of CDCA (Pc/ CDCA $=1: 50)$ and the sample without a co-adsorbent, though the response of $\mathrm{Pc} / \mathrm{CDCA}=1: 10$ is very close to that of $\mathrm{Pc} /$ $\mathrm{CDCA}=1: 50$ sample, whereas the response of the $\mathrm{Pc} / \mathrm{OA}=$ 1:10 sample is closer to that of the pure Pc sample.

2.4. Solar Cells. To study the effect of aggregation of photocurrent generation in solar cells, silver electrodes were deposited on top of the samples with Spiro hole transporting layer, and standard current-voltage $(I-V)$ characteristics where measured in the dark and under "one sun" (AM 1.5) illumination. Typical $I-V$ curves are presented in Figure 10 for

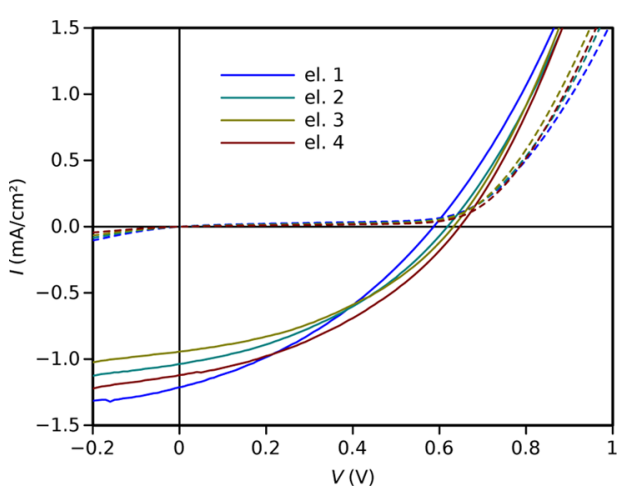

Figure 10. Current-voltage characteristics of Pc/CDCA $=1: 20$ sample in the dark (dashed lines) and under illumination (solid lines). One sample had four electrode pairs with an overlap area of roughly 2 $\mathrm{mm}^{2}$.

Pc/CDCA = 1:20 sample. Each sample had four electrode pairs with an overlap area of roughly $2 \mathrm{~mm}^{2}$. The variation in $I-V$ curves of different electrode pairs on the sample was reasonably small, as can be seen in Figure 10.

The obtained PCEs were in the range $0.1-0.4 \%$ for the samples discussed here. This is roughly 1 order in magnitude lower than the efficiencies reported for the best ssDSSCs with the same Pc. ${ }^{31}$ However, the primary goal of this part is to compare the results of ultrafast spectroscopy study of the primary photoreactions with the properties of the complete ssDSSCs. Therefore, the samples were optimized to get most out of the spectroscopy measurements but not to achieve the highest PCE. The aim is also to get a fair comparison of different sensitizer/co-adsorbate combinations. This means in particular that all samples have to be prepared with the same $\mathrm{TiO}_{2}$ base structure to ensure that the samples infiltrated by Spiro similarly. The thickness of the $\mathrm{TiO}_{2}$ film was selected such that the absorption of Pc at maximum (Q-band) is close to $1(\mathrm{OD})$, which is the maximum reasonable value for accurate pump-probe measurement. As the result, the absorption of the sample with a high relative concentration of co-adsorbate (e.g. $\mathrm{Pc} / \mathrm{CDCA}=1: 100$ in sensitization solution) was rather low, around 0.15 (OD), which is still sufficient for TA measurements but far from optimum for efficient power conversion.

The parameter of interest for this study is the internal conversion efficiency (ICE), or the ratio of the generated electrons to absorbed photons, $\phi_{\mathrm{ICE}}$. The electron flux can be obtained directly from the measured short circuit current, $I_{\mathrm{sc}}$ ( $I$ at $V=0$ in Figure 10). However, the number of absorbed photons cannot be measured directly and has to be evaluated from the available data. This number can be evaluated from the excitation photon flux and sample absorption.

The Pc samples have main absorption bands in the range $580-720 \mathrm{~nm}$, which is commonly referred to as the Q-band area. Another absorption band commonly referred to as the Soret band is at wavelengths shorter than $400 \mathrm{~nm}$ and its intensity is few times lower than that of the Q-band. Also, the sun intensity is maximal in the Q-band area and decreases sharply at $<400 \mathrm{~nm}$. Therefore, the spectral area of significance for the studied samples is the Q-band area, and for all samples, it is within the range $550-750 \mathrm{~nm}$. The sunlight intensity does not change much within this range having the average value $P_{650}=1.24 \mathrm{~W} \mathrm{~m}^{-2} \mathrm{~nm}^{-1}$ with standard deviation $0.12 \mathrm{~W} \mathrm{~m}^{-2}$ $\mathrm{nm}^{-1} .^{44}$ Therefore, to compare light harvesting efficiencies of the samples, average absorptances, $a_{\mathrm{av}}$, were calculated in the range 550-750 nm. As an example, the values of $a_{\mathrm{av}}$ are 0.37 , 0.29 , and 0.045 for Pc/CDCA samples with ratios 1:0, 1:10, and 1:100, respectively, which means that the pure Pc sample (1:0) absorbs $37 \%$ of photons in the range $550-750 \mathrm{~nm}$, and the $1: 100$ sample absorbs only $4.5 \%$ of photons in this range (see Figure S14 in Supporting Information).

2.4.1. Photocurrent Generation Efficiency. To compare the quantum efficiency of the photocurrent generation, the short circuit $I_{\mathrm{sc}}$ was divided by $a_{\mathrm{av}}$, to account for absorbed photons only. Reference samples without the co-adsorbate were prepared a few times (five series) during the tests, and the ratios $I_{\text {norm }}=I_{\mathrm{sc}} / a_{\mathrm{av}}$ for these samples were averaged and used to normalized the ratios obtained for all other samples, thus calculating "relative" current values $I_{\text {rel }}(x)=I_{\text {norm }}(x) / I_{\text {norm }}(0)$, where $x$ is the co-adsorbate concentration and $I_{\text {norm }}(0)$ is the average or all samples without the co-adsorbate. The results of calculations are presented in Figure 11 as a function of the

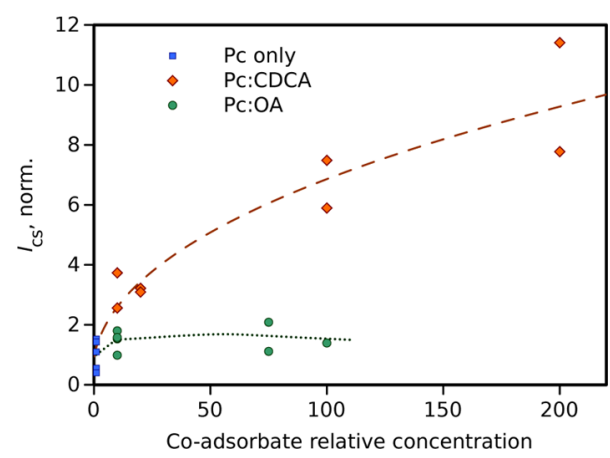

Figure 11. Relative photocurrent generation efficiencies, $I_{\text {rel, }}$ plotted as a function of relative co-adsorbate concentration. Values are normalized to the average of the samples without the co-adsorbate. The lines are indicating trends for visual guidance.

relative co-adsorbate concentration and show increase or decrease of ICE of the sample relative to the average value of samples without the co-adsorbate. Although there is relatively large deviation of the result for the samples with the same composition, addition of CDCA has a clear effect of gradual increase of the quantum efficiency of the photocurrent generation. According to this estimation, the quantum efficiency is roughly 3 times higher for 1:10 and 1:20 samples, and it increases furthermore for 1:100 and 1:200 samples.

The same results are summarized in Table 1 by averaging relative efficiencies $\left(I_{\text {rel }}\right)$ for the samples of the same composition. Also, it has to be noted that the standard deviation of the relative efficiencies were rather high, $20-50 \%$. 
Table 1. Relative Efficiency of the CS at the SemiconductorOrganic Interface of Spiro-Containing Samples Estimated from TA and Photocurrent Measurements ${ }^{a}$

\begin{tabular}{lccc}
\multicolumn{1}{c}{ sample } & $\Delta A_{\text {rel }}(2 \mathrm{ps})$ & $\Delta A_{\text {rel }}(2 \mathrm{~ns})$ & $I_{\text {rel }}$ \\
Pc only & 0.15 & 0.12 & 1.0 \\
Pc/CDCA $=1: 10$ & 0.25 & 0.16 & 3.1 \\
Pc/CDCA $=1: 20$ & & & 3.2 \\
Pc/CDCA $=1: 50$ & 0.29 & 0.14 & \\
Pc/CDCA $=1: 100$ & 0.27 & 0.20 & 6.7 \\
Pc/CDCA = 1:200 & & & 9.6 \\
Pc/OA = 1:10 & 0.13 & 0.06 & 1.5 \\
Pc/OA $=1: 75$ & & & 1.6 \\
Pc/OA $=1: 100$ & 0.16 & 0.13 & 1.4
\end{tabular}

$a_{\text {The relative }}$ TA values $\left(\Delta A_{\text {rel }}()\right)$ were calculated by taking absorbance change at $1250 \mathrm{~nm}$ at 2 ps and $2 \mathrm{~ns}$ delay time and dividing by the change at $860 \mathrm{~nm}$ right after the excitation, and relative photocurrents $\left(I_{\text {rel }}\right)$ are the short-circuit currents of the samples with to that without the co-adsorbate and normalized to average sample absorptance $\left(a_{\mathrm{av}}\right)$ in the 550-750 $\mathrm{nm}$ range (see the text for details).

The efficiency estimation of the long-distance CS based on spectroscopy is more complex as it requires quantitative knowledge of the absorption spectra of the intermediate states of interest, namely, primary excited sensitizers and states involved in photocurrent generation. The conduction band electrons in $\mathrm{TiO}_{2}$ have no distinct spectroscopic features which can be seen on top of TA responses of Pc and Spiro. However, the Spiro cation has two features, the band at $530 \mathrm{~nm}$ and the broadband absorption at $>1000 \mathrm{~nm}$. The NIR absorption of Spiro $^{+}$seems to be a better choice because the Pc cation and anion have negligible absorption at the red side of the measured range. Therefore, the TA response at $1250 \mathrm{~nm}$ can be used as an indicator of the Spiro $^{+}$yield at least at delay time $>1 \mathrm{ps}$, that is, after relaxation of the singlet excited state of Pc which also has some absorption at this wavelength, as can be seen in response of all samples at short delay time $(<0.1 \mathrm{ps})$. The primary excited sensitizer in our case is the singlet excited state of Pc. The absorption at a short delay time (e.g. at 0.02 ps in Figure 9) is the strongest at $860 \mathrm{~nm}$, and it can be taken as the measure of the number of excited Pcs. Therefore, the ratio of the absorbances at $1250 \mathrm{~nm}$ at a long delay time to that at 860 $\mathrm{nm}$ right after the excitation, $\Delta A_{\text {rel }}=\Delta A_{1260} / \Delta A_{860}$, must be proportional to quantum yield of (absorbed) photons to hole conversion. These relative absorption changes were calculated for two delay times, 2 ps and 2 ns, and presented in Table 1 (denoted as $\Delta A_{\text {rel }}(2 \mathrm{ps})$ and $\Delta A_{\text {rel }}(2 \mathrm{~ns})$, respectively).

A common trend for both $\Delta A_{\text {rel }}$ and $I_{\text {rel }}$ seen in Table 1 is the increase in the efficiency of Spiro ${ }^{+}$and current generation with the increase of CDCA concentration, though the increase of $I_{\text {rel }}$ is larger than of $\Delta A_{\text {rel }}$. According to the TA responses discussed above, this increase can be attributed to the lower Pc aggregation upon addition of CDCA, suppressing the undesired intra-aggregate CS. Interestingly, at a longer delay time, $2 \mathrm{~ns}$, the yield is virtually the same for three first samples in the table. This may be interpreted in favor of a relatively fast hole diffusion to the electrode, so that slow (nanosecond) CRs does not affect photocurrent generation. Though TA measurements are rather difficult after top electrode deposition and were not carried out.

Both TA and photocurrent measurements do not show significant increase in photon-to-current efficiency on addition of OA co-adsorbate, although the absorption spectra (Figure
$2 b)$ suggest a gradual decrease in the aggregation degree. One possible explanation for this difference between CDCA and OA is the length difference between the molecules. A rough estimation of the CDCA molecule length is $1.2 \mathrm{~nm}$, which is close to or a little shorter than the length of Pc molecules standing upright on the $\mathrm{TiO}_{2}$ surface. The length of $\mathrm{OA}$ is roughly $1.6 \mathrm{~nm}$, or longer than the Pc molecule, which may prevent a sufficient contact between the Pc and Spiro needed for efficient electronic interactions at the PclSpiro interface and may thus explain the lower hole transfer efficiency to Spiro in the OA-containing samples. However, this explanation is in contradiction with the observed change in the Pc absorption spectrum after the deposition of Spiro. Still it seems to be reasonable to suggest that some structural difference between the Pc/CDCA and Pc/OA SAMs is responsible for the difference in the photophysics of the samples. Another obvious reason for the relatively poor results with OA co-adsorbate is rather fast sample degradation especially at higher OA concentrations, as was mentioned above.

The absolute value of the quantum efficiency can be estimated using excitation power density, $P_{650}$, short circuit current, $I_{\mathrm{sc}}$ and average absorptances, $a_{\mathrm{av}}$ (see Supporting Information for the details of calculations). This estimation suggests that the quantum yield of photon-to-electron conversion is roughly $13 \%$ for the samples without the coadsorbate, close to $40 \%$ for $1: 10$ and 1:20 Pc/CDCA samples, and approaches $100 \%$ for 1:100 and 1:200 samples. The latter is least accurate as the estimation accuracy depends critically on average absorption calculation, which in turn depends on accuracies of subtracting "background absorption" of $\mathrm{TiO}_{2}$ and spectra correction procedure after the deposition of Spiro.

The absolute values of external PCEs for this series was higher for Pc/CDCA = 1:10 and 1:20 samples than for the samples without CDCA by a factor of 2 ( 0.4 vs $0.15 \%)$. For $1: 100$ samples the efficiency dropped down to that of the samples without CDCA, but average absorptance, $a_{\mathrm{av}}$, of the $1: 100$ sample is only 0.045 (in the $550-750 \mathrm{~nm}$ range), whereas for the sample without CDCA $a_{\mathrm{av}} \approx 0.5$, or the 1:100 sample uses absorbed photons 10 times more efficiently than the sample without CDCA. The 1:100 sample is not efficient in absorbing light because its optical density is only 0.12 at the maximum of the Q-band (695 nm) and the spectrum band width is roughly $30 \mathrm{~nm}$ only. One obvious approach to increase cell efficiency could be to increase the thickness of $\mathrm{TiO}_{2}$ nanoparticle film, though in this case the thickness must be increased by 10 times at least (to be $\geq 20 \mu \mathrm{m}$ ), which will create another problem of pore filling with the HTM. ${ }^{15}$

Another approach to increase the PCE of Pc-based solar cells is to use co-adsorbates with chromophores, which would work as a light harvesting subsystem in a way similar to that reported by M'Sabah et al., ${ }^{45}$ absorbing the solar light and delivering the excited state energy to Pc by the nonradiating energy transfer mechanism. This approach may also help to solve another problem of Pc sensitizers, weak absorption in the green part of the spectrum, if the light harvesting co-adsorbate is designed to cover the green-yellow part of the spectrum. Also, mixing Pc with sensitizers utilizing the green-yellow part of the spectrum, such as porphyrins, ${ }^{17}$ may also help to solve the problem.

\section{CONCLUSIONS}

Aggregation of Pcs is usually considered as the most detrimental factor to the efficiency of Pc-sensitized DSSCs. The results reported here are in full agreement with this notion 
and indicate that intra-aggregate $\mathrm{CS}$ is the main mechanism of the excited state deactivation. A traditional method to reduce aggregation is to use co-adsorbate molecules. One of the most widely used compounds for this purpose is CDCA. For comparison, we have used $\mathrm{OA}$ as well. Addition of the coadsorbate reduces the aggregation gradually, as can be seen from the steady-state absorption spectra change and transient responses of the samples.

Addition of a hole-transporting layer of Spiro-MeOTAD changes the primary CS events quite drastically, switching the main reaction route to the $\mathrm{CS}$ at the organic-organic interface, PclSpiro, instead of the electron injection at $\mathrm{TiO}_{2} \mid \mathrm{Pc}$. In the case of aggregated Pc layer deposited without the co-adsorbate, the intramolecule interactions compete with the CS and reduce the efficiency of CS at the PclSpiro interface. However, mixing Pc with CDCA at ratios larger than 1:20 (in sensitizing solution) reduces the aggregation effect to a negligible level, thus generating the $\mathrm{Pc}^{-} \mid \mathrm{Spiro}^{+}$state with almost unity yield.

The increase in quantum yield of photocurrent generation was also confirmed by depositing top electrodes on the $\mathrm{TiO}_{2} \mathrm{I}$ PclSpiro structures and comparing short circuit currents of the cells. An estimation suggests that the quantum yield of photonto-current conversion is less than $15 \%$ for samples without the co-adsorbate but can be increased to almost unity by mixing Pc with CDCA at ratio 1:100. However, at this ratio, the PCE is few times lower than for the best sample in the series because of very low absorption of the sample (OD $<0.15$ at the Q-band maximum).

\section{METHODS AND MATERIALS}

4.1. Materials. EtOH ( $\geq 99.5 \%$ by mass) was purchased from Altia Plc. $2,2^{\prime}, 7,7^{\prime}$-Tetrakis $(N, N$-di- $p$-methoxyphenylamino)-9,9'-spirobifluorene (Spiro-MeOTAD or Spiro) was purchased from Lumtec (Luminescence Technology Corp.). $\mathrm{TiO}_{2}$ nanoparticle paste was purchased from Solaronix (TiNanoxide T/SP) and from Dyesol (18NR-T). CDCA and OA were used as co-adsorbates to reduce aggregation in the $\mathrm{Pc}$ monolayers. They were purchased from Sigma-Aldrich along with all other solvents and chemicals and used without further purification. FTO-coated glass substrates (TEC7) were purchased from Sigma-Aldrich and cleaned as described below. Zinc carboxyphthalocyanine (Pc, Figure 1) derivative used in this study and also known as TT1 was synthesized according to a protocol described elsewhere. ${ }^{23}$

4.2. Samples. The FTO-coated glass substrates were cut to approx. $20 \times 20 \mathrm{~mm}$ substrates and patterned by mechanical etching with a grinding tool. After the patterning, the substrates were washed by 15 min sonication in $2 \%$ aqueous Hellmanex III solution, followed by $15 \mathrm{~min}$ sonication in 2-propanol, and dried under vacuum.

A thin $\mathrm{TiO}_{2}$ compact layer was used as a hole-blocking layer. The layer was prepared by spin-coating (3000 rpm, $30 \mathrm{~s}$ ) a 0.22 $\mathrm{M}$ solution of titanium isopropoxide in acidic EtOH (13 mM of $\mathrm{HCl}$ ) onto the cleaned and patterned FTO substrates, followed by sintering at $475^{\circ} \mathrm{C}$ for $45 \mathrm{~min}$ in air. For better film quality, the spin-coating and sintering procedure was repeated.

$\mathrm{TiO}_{2}$ mesoporous layers were prepared by screen-printing and by spin-coating. For the screen-printed layers, the $\mathrm{Ti}$ Nanoxide T/SP paste was screen-printed on top of the substrates through a $77-55$ mesh (mesh thickness, $87 \mu \mathrm{m}$ ). For the spin-coated layers, the Dyesol $18 \mathrm{NR}-\mathrm{T}$ paste was diluted in $\mathrm{EtOH}$ at a 2:5 weight ratio and spin-coated (1000 rpm, $45 \mathrm{~s})$ onto the substrates. After depositing the $\mathrm{TiO}_{2}$ mesoporous layer, the substrates were sintered again at $475{ }^{\circ} \mathrm{C}$. The $\mathrm{TiO}_{2}$ nanoparticle film thickness was approx. $2.5 \mu \mathrm{m}$ for the screenprinted layers and approx. $800 \mathrm{~nm}$ for the spin-coated layers, respectively. Typical cross-section electron microscopy images are shown in Supporting Information Figure S1.

To increase the surface roughness in the $\mathrm{TiO}_{2}$ layer and therefore to adsorb more dye, the $\mathrm{TiO}_{2}$ substrates were treated with aqueous $\mathrm{TiCl}_{4}$. A $2 \mathrm{M}$ aqueous stock solution of $\mathrm{TiCl}_{4}$ was prepared: $1.56 \mathrm{~mL}$ of Milli-Q $\mathrm{H}_{2} \mathrm{O}$ was frozen with a stir bar, $440 \mu \mathrm{L}$ of $\mathrm{TiCl}_{4}$ was added dropwise in an ice bath, and the solution was stirred for $10 \mathrm{~min}$. The $2 \mathrm{M}$ stock solution was then diluted into $0.02 \mathrm{M}$, and the substrates were immersed into this solution at $70{ }^{\circ} \mathrm{C}$ for $30 \mathrm{~min}$ and washed thoroughly with Milli- $\mathrm{QH}_{2} \mathrm{O}$. The substrates were sintered after the $\mathrm{TiCl}_{4}$ treatment, and after sintering they were ready for staining.

To deposit SAMs of the Pc with and without the coadsorbates, the substrates were immersed into solutions of the $\mathrm{Pc}$, typically for $20 \mathrm{~h}$. The solutions were prepared in $t-\mathrm{BuOH} /$ $\mathrm{MeCN} \mathrm{1:1} \mathrm{(vol/vol)} \mathrm{at} 0.1 \mathrm{mmol} / \mathrm{L}$ concentration. The coadsorbates were added into the solutions at different Pc to coadsorbate molar ratios ranging from $1: 10$ to $1: 100$ or using concentration of co-adsorbates up to $10 \mathrm{mM}$. After the reaction, the substrates were removed from the Pc solutions and washed by immersing them for 5 min into the $t-\mathrm{BuOH}$ / $\mathrm{MeCN}$ mixture.

The sensitized $\mathrm{TiO}_{2}$ samples were coated with a hole transporting layer, Spiro, following a reported procedure. Spiro was doped with bis(trifluoromethane)sulfonimide lithium salt (LiTFSI) and 4-tert-butylpyridine $(t-\mathrm{BP})$ for a better hole conductivity. The hole transporting layer was prepared by spincoating typically a $214 \mathrm{~g} / \mathrm{L}$ solution of Spiro with $23 \mathrm{mM}$ of LiTFSI and $233 \mathrm{mM}$ of $t$-BP in anhydrous chlorobenzene onto the sensitized $\mathrm{TiO}_{2}$ substrates. The solution was allowed to diffuse into the $\mathrm{TiO}_{2}$ mesoporous layer for $30 \mathrm{~s}$ after the spreading. Then, the samples were rotated for $60 \mathrm{~s}$ at $1000 \mathrm{rpm}$. To ensure that sufficient amount of Spiro was deposited, crosssection scanning electron microscopy (SEM) images of the samples were taken, in which a thin Spiro layer on top of the $\mathrm{TiO}_{2}$ film can be seen (see Supporting Information Figure S1).

For the solar cell measurements, the sample structure was finalized by thermally evaporating a $75 \mathrm{~nm} \mathrm{Ag}$ electrode on top of the sample structure at a high vacuum (approx. $10^{-6} \mathrm{mbar}$ ). The electrode areas were typically $2-3 \mathrm{~mm}^{2}$.

4.3. Instruments. Absorption spectra of the samples were measured using a Shimadzu UV-1800 UV-Vis-NIR spectrophotometer in the range $350-850 \mathrm{~nm}$.

The sample morphology was investigated using a fieldemission SEM (Carl Zeiss Ultra 55).

Standard solar cell characterization was carried out by measuring $I-V$ curves (Agilent Tech. E5272A source/ monitoring unit) in the dark and under one sun (AM 1.5) illumination (Sciencetech SS150 solar simulator).

Ultrafast TA responses of the samples were measured using a pump-probe system described previously. ${ }^{46,47}$ Briefly, the samples were excited by laser pulses at $695 \mathrm{~nm}$ (Libra F, Coherent Inc., coupled with Topas C, Light Conversion Ltd.). A white continuum generator (sapphire crystal) was used to produce the probe beam. The TA responses were measured using an ExciPro TA spectrometer (CDP, Inc.) equipped with a CCD array for the visible spectral range $(460-770 \mathrm{~nm})$ and an InGa diode array for the NIR wavelengths (840-1045 and $1050-1260 \mathrm{~nm}$ ). The pulse repetition rate of the laser system was $1 \mathrm{kHz}$ and the spectra were typically acquired by averaging 
over $5 \mathrm{~s}$. Typical time resolution of the instrument was $100 \mathrm{fs}$. Data collected in the three wavelength ranges were fitted globally to a sum of exponential functions or a combination of exponential, stretched-exponential, and distributed decay models. ${ }^{48}$ The fit program accounted for the instrument response (through a deconvolution process) and did the group velocity dispersion compensation. Therefore, the generated time-resolved spectra were free of dispersion and had an "improved" time resolution.

\section{ASSOCIATED CONTENT}

\section{Supporting Information}

The Supporting Information is available free of charge on the ACS Publications website at DOI: 10.1021/acsomega.8b00600.

Cross-section SEM images of the studied samples, absorption spectra of Pc in solutions, details of spectra fitting in the Q-band region, spectra fits, absorption spectra of $\mathrm{Pc} / \mathrm{CDCA}=1: 10$ and $\mathrm{Pc} / \mathrm{OA}=1: 10$ samples, normalized TA decays of Pc/CDCA $=1: 50$ with Spiro, time-resolved and component TA spectra of Pc/CDCA = 1:10, pure PclSpiro, Pc/CDCA, and PcOA 1:10 with Spiro, absorptance spectra of 1:0, 1:10, and 1:100 Pc/ CDCA samples used photocurrent measurements, and dependence of efficiency on the relative concentration of CDCA (PDF)

\section{AUTHOR INFORMATION}

\section{Corresponding Authors}

*E-mail: tomas.torres@uam.es (T.T.).

*E-mail: nikolai.tkachenko@tut.fi (N.V.T.).

ORCID $\odot$

Kirsi Virkki: 0000-0003-4976-3917

Tomás Torres: 0000-0001-9335-6935

Nikolai V. Tkachenko: 0000-0002-8504-2335

Notes

The authors declare no competing financial interest.

\section{ACKNOWLEDGMENTS}

K.V. acknowledges the Doctoral Programme of Tampere University of Technology for the financial support. N.V.T. acknowledges NATO SPS project no. 985043. Financial support from Comunidad de Madrid, Spain (S2013/MIT2841, FOTOCARBON) and MINECO, Spain (CTQ201452869-P and CTQ2017-85393-P) is acknowledged. IMDEA Nanociencia acknowledges support from the "Severo Ochoa" Programme for Centres of Excellence in R\&D (MINECO, grant SEV-2016-0686).

\section{REFERENCES}

(1) Yella, A.; Lee, H.-W.; Tsao, H. N.; Yi, C.; Chandiran, A. K.; Nazeeruddin, M. K.; Diau, E. W.-G.; Yeh, C.-Y.; Zakeeruddin, S. M.; Grätzel, M. Porphyrin-Sensitized Solar Cells with Cobalt (II/III)Based Redox Electrolyte Exceed 12 Percent Efficiency. Science 2011, 334, 629-634.

(2) Ye, M.; Wen, X.; Wang, M.; Iocozzia, J.; Zhang, N.; Lin, C.; Lin, Z. Recent Advances in Dye-Sensitized Solar Cells: from Photoanodes, Sensitizers and Electrolytes to Counter Electrodes. Mater. Today 2015, $18,155-162$.

(3) Hagfeldt, A.; Boschloo, G.; Sun, L.; Kloo, L.; Pettersson, H. DyeSensitized Solar Cells. Chem. Rev. 2010, 110, 6595-6663.

(4) Asbury, J. B.; Hao, E.; Wang, Y.; Ghosh, H. N.; Lian, T. Ultrafast Electron Transfer Dynamics from Molecular Adsorbates to Semi- conductor Nanocrystalline Thin Films. J. Phys. Chem. B 2001, 105, $4545-4557$.

(5) Furube, A.; Katoh, R.; Hara, K. Electron injection dynamics in dye-sensitized semiconductor nanocrystalline films. Surf. Sci. Rep. 2014, 69, 389-441.

(6) Martín, C.; Ziółek, M.; Douhal, A. Ultrafast and fast charge separation processes in real dye-sensitized solar cells. J. Photochem. Photobiol., C 2016, 26, 1-30.

(7) Němec, H.; Rochford, J.; Taratula, O.; Galoppini, E.; Kužel, P.; Polívka, T.; Yartsev, A.; Sundström, V. Influence of the ElectronCation Interaction on Electron Mobility in Dye-Sensitized $\mathrm{ZnO}$ and $\mathrm{TiO}_{2}$ Nanocrystals: A Study Using Ultrafast Terahertz Spectroscopy. Phys. Rev. Lett. 2010, 104, 197401.

(8) Milot, R. L.; Moore, G. F.; Crabtree, R. H.; Brudvig, G. W.; Schmuttenmaer, C. A. Electron Injection Dynamics from Photoexcited Porphyrin Dyes into $\mathrm{SnO}_{2}$ and $\mathrm{TiO}_{2}$ Nanoparticles. J. Phys. Chem. C 2013, 117, 21662-21670.

(9) Imahori, H.; Kang, S.; Hayashi, H.; Haruta, M.; Kurata, H.; Isoda, S.; Canton, S. E.; Infahsaeng, Y.; Kathiravan, A.; Pascher, T.; Chábera, P.; Yartsev, A. P.; Sundström, V. Photoinduced Charge Carrier Dynamics of $\mathrm{Zn}$-Porphyrin- $\mathrm{TiO}_{2}$ Electrodes: The Key Role of Charge Recombination for Solar Cell Performance. J. Phys. Chem. A 2011, 115, 3679-3690.

(10) Antila, L. J.; Myllyperkiö, P.; Mustalahti, S.; Lehtivuori, H.; Korppi-Tommola, J. Injection and Ultrafast Regeneration in DyeSensitized Solar Cells. J. Phys. Chem. C 2014, 118, 7772-7780.

(11) Cappel, U. B.; Smeigh, A. L.; Plogmaker, S.; Johansson, E. M. J.; Rensmo, H.; Hammarström, L.; Hagfeldt, A.; Boschloo, G. Characterization of the Interface Properties and Processes in Solid State DyeSensitized Solar Cells Employing a Perylene Sensitizer. J. Phys. Chem. C 2011, 115, 4345-4358.

(12) Howard, I. A.; Meister, M.; Baumeier, B.; Wonneberger, H.; Pschirer, N.; Sens, R.; Bruder, I.; Li, C.; Müllen, K.; Andrienko, D.; Laquai, F. Two Channels of Charge Generation in Perylene Monoimide Solid-State Dye-Sensitized Solar Cells. Adv. Energy Mater. 2014, 4, 1300640.

(13) Humphry-Baker, N.; Driscoll, K.; Rao, A.; Torres, T.; Snaith, H. J.; Friend, R. H. Time-Evolution of Poly(3-Hexylthiophene) as an Energy Relay Dye in Dye-Sensitized Solar Cells. Nano Lett. 2012, 12, 634-639.

(14) Qin, P.; Sanghyun, P.; Dar, M. I.; Rakstys, K.; ElBatal, H.; AlMuhtaseb, S. A.; Ludwig, C.; Nazeeruddin, M. K. Weakly Conjugated Hybrid Zinc Porphyrin Sensitizers for Solid-State Dye-Sensitized Solar Cells. Adv. Funct. Mater. 2016, 26, 5550-5559.

(15) Melas-Kyriazi, J.; Ding, I.-K.; Marchioro, A.; Punzi, A.; Hardin, B. E.; Burkhard, G. F.; Tétreault, N.; Grätzel, M.; Moser, J.-E.; McGehee, M. D. The Effect of Hole Transport Material Pore Filling on Photovoltaic Performance in Solid-State Dye-Sensitized Solar Cells. Adv. Energy Mater. 2011, 1, 407-414.

(16) Urbani, M.; Grätzel, M.; Nazeeruddin, M. K.; Torres, T. MesoSubstituted Porphyrins for Dye-Sensitized Solar Cells. Chem. Rev. 2014, 114, 12330-12396.

(17) Ragoussi, M.-E.; Ince, M.; Torres, T. Recent Advances in Phthalocyanine-Based Sensitizers for Dye-Sensitized Solar Cells. Eur. J. Org. Chem. 2013, 6475-6489.

(18) Imahori, H.; Umeyama, T.; Ito, S. Large $\pi$-Aromatic Molecules as Potential Sensitizers for Highly Efficient Dye-Sensitized Solar Cells. Acc. Chem. Res. 2009, 42, 1809-1818.

(19) Higashino, T.; Imahori, H. Porphyrins as excellent dyes for dyesensitized solar cells: recent developments and insights. Dalton Trans. 2015, 44, 448-463.

(20) Brogdon, P.; Cheema, H.; Delcamp, J. H. Near-InfraredAbsorbing Metal-Free Organic, Porphyrin, and Phthalocyanine Sensitizers for Panchromatic Dye-Sensitized Solar Cells. ChemSusChem 2018, 11, 86-103.

(21) Krishna, N. V.; Krishna, J. V. S.; Singh, S. P.; Giribabu, L.; Han, L.; Bedja, I.; Gupta, R. K.; Islam, A. Donor- $\pi$-Acceptor Based Stable Porphyrin Sensitizers for Dye-Sensitized Solar Cells: Effect of $\pi$ Conjugated Spacers. J. Phys. Chem. C 2017, 121, 6464-6477. 
(22) Li, X.; Xu, B.; Liu, P.; Hu, Y.; Kloo, L.; Hua, J.; Sun, L.; Tian, H. Molecular engineering of $\mathrm{D}-\mathrm{A}-\pi-\mathrm{A}$ sensitizers for highly efficient solid-state dye-sensitized solar cells. J. Mater. Chem. A 2017, 5, 31573166.

(23) Cid, J.-J.; Yum, J.-H.; Jang, S.-R.; Nazeeruddin, M. K.; MartínezFerrero, E.; Palomares, E.; Ko, J.; Grätzel, M.; Torres, T. Molecular Cosensitization for Efficient Panchromatic Dye-Sensitized Solar Cells. Angew. Chem., Int. Ed. 2007, 46, 8358-8362.

(24) Ragoussi, M.-E.; Cid, J.-J.; Yum, J.-H.; de la Torre, G.; Di Censo, D.; Grätzel, M.; Nazeeruddin, M. K.; Torres, T. Carboxyethynyl Anchoring Ligands: A Means to Improving the Efficiency of Phthalocyanine-Sensitized Solar Cells. Angew. Chem., Int. Ed. 2012, 51, 4375-4378.

(25) Li, Y.; Lu, P.; Yan, X.; Jin, L.; Peng, Z. Non-aggregated hyperbranched phthalocyanines: single molecular nanostructures for efficient semi-opaque photovoltaics. RSC Adv. 2013, 3, 545-558.

(26) Tejerina, L.; Martínez-Díaz, M. V.; Nazeeruddin, M. K.; Torres, $\mathrm{T}$. The Influence of Substituent Orientation on the Photovoltaic Performance of Phthalocyanine-Sensitized Solar Cells. Chem.-Eur. J. 2016, 22, 4369-4373.

(27) Wang, M.; Plogmaker, S.; Humphry-Baker, R.; Pechy, P.; Rensmo, H.; Zakeeruddin, S. M.; Grätzel, M. Molecular-Scale Interface Engineering of Nanocrystalline Titania by Co-adsorbents for Solar Energy Conversion. ChemSusChem 2012, 5, 181-187.

(28) Günsel, A.; Güzel, E.; Bilgiçli, A. T.; Şişman, I.; Yarasir, M. N. Synthesis of non-peripheral thioanisole-substituted phthalocyanines: Photophysical, electrochemical, photovoltaic, and sensing properties. J. Photochem. Photobiol., A 2017, 348, 57-67.

(29) Jungsuttiwong, S.; Sirithip, K.; Prachumrak, N.; Tarsang, R.; Sudyoadsuk, T.; Namuangruk, S.; Kungwan, N.; Promarak, V.; Keawin, T. Significant enhancement in the performance of porphyrin for dye-sensitized solar cells: aggregation control using chenodeoxycholic acid. New J. Chem. 2017, 41, 7081-7091.

(30) Hsu, C.-Y.; Chen, Y.-C.; Lin, R. Y.-Y.; Ho, K.-C.; Lin, J. T. Solidstate dye-sensitized solar cells based on spirofluorene (spiroOMeTAD) and arylamines as hole transporting materials. Phys. Chem. Chem. Phys. 2012, 14, 14099-14109.

(31) Li, X.; Xu, B.; Liu, P.; Hu, Y.; Kloo, L.; Hua, J.; Sun, L.; Tian, H. Molecular engineering of $\mathrm{D}-\mathrm{A}-\pi-\mathrm{A}$ sensitizers for highly efficient solid-state dye-sensitized solar cells. J. Mater. Chem. A 2017, 5, 31573166.

(32) Nojiri, T.; Alam, M. M.; Konami, H.; Watanabe, A.; Ito, O. Photoinduced Electron Transfer from Phthalocyanines to Fullerenes $\left(\mathrm{C}_{60}\right.$ and $\left.\mathrm{C}_{70}\right)$. J. Phys. Chem. A 1997, 101, 7943-7947.

(33) Ou, Z.; Jiang, Z.; Chen, N.; Huang, J.; Shen, J.; Kadish, K. M. Electrochemistry and spectroelectrochemistry of tetra- $\alpha$-substituted metallophthalocyanines. J. Porphyrins Phthalocyanines 2008, 12, 11231133.

(34) Grätzel, M.; Bach, U.; Lupo, D.; Comte, P.; Moser, J. E.; Weissörtel, F.; Salbeck, J.; Spreitzer, H. Solid-State Dye-Sensitized Mesoporous $\mathrm{TiO}_{2}$ Solar Cells with High Photon-to-Electron Conversion Efficiencies. Nature 1998, 395, 583-585.

(35) Virkki, K.; Hakola, H.; Urbani, M.; Tejerina, L.; Ince, M.; Martínez-Díaz, M.; Torres, T.; Golovanova, V.; Golovanov, V.; Tkachenko, N. V. Photoinduced Electron Injection from Zinc Phthalocyanines into Zinc Oxide Nanorods: Aggregation Effects. J. Phys. Chem. C 2017, 121, 9594-9605.

(36) Kakade, S.; Ghosh, R.; Palit, D. K. Excited State Dynamics of Zinc-Phthalocyanine Nanoaggregates in Strong Hydrogen Bonding Solvents. J. Phys. Chem. C 2012, 116, 15155-15166.

(37) Guldi, D. M.; Zilbermann, I.; Gouloumis, A.; Vázquez, P.; Torres, T. Metallophthalocyanines: Versatile Electron-Donating Building Blocks for Fullerene Dyads. J. Phys. Chem. B 2004, 108, 18485-18494.

(38) Fukuzumi, S.; Ohkubo, K.; Ortiz, J.; Gutiérrez, A. M.; Fernández-Lázaro, F.; Sastre-Santos, Á. Formation of a Long-Lived Charge-Separated State of a Zinc Phthalocyanine-Perylenediimide Dyad by Complexation with Magnesium Ion. Chem. Commun. 2005, 30, 3814-3816.
(39) Mack, J.; Stillman, M. J. Photochemical Formation of the Anion Radical of Zinc Phthalocyanine and Analysis of the Absorption and Magnetic Circular Dichroism Spectral Data. Assignment of the Optical Spectrum of $[\mathrm{ZnPc}(-3)]^{-}$. J. Am. Chem. Soc. 1994, 116, 1292-1304. (40) Hakola, H.; Sariola-Leikas, E.; Efimov, A.; Tkachenko, N. V. Effect of Hole Transporting Material on Charge Transfer Processes in Zinc Phthalocyanine Sensitized ZnO Nanorods. J. Phys. Chem. C 2016, $120,7044-7051$.

(41) Konarev, D. V.; Khasanov, S. S.; Lyubovskaya, R. N. Effect of Deprotonation and Reduction on the Molecular Structure and Optical and Magnetic Properties of Metal-Free Phthalocyanine $(\mathrm{Pc})$ : Comparison of $\mathrm{H} 2 \mathrm{Pc}-$ and $\mathrm{HPc}-$ Anions. Asian J. Org. Chem. 2017, 6, 1028-1033.

(42) Lemmetyinen, H.; Tkachenko, N.; Efimov, A.; Niemi, M. Transient states in photoinduced electron transfer reactions of porphyrin- and phthalocyanine-fullerene dyads. J. Porphyrins Phthalocyanines 2009, 13, 1090-1097.

(43) Hakola, H.; Perros, A. P.; Myllyperkiö, P.; Kurotobi, K.; Lipsanen, H.; Imahori, H.; Lemmetyinen, H.; Tkachenko, N. V. Photo-Induced Electron Transfer at Nanostructured SemiconductorZinc Porphyrin Interface. Chem. Phys. Lett. 2014, 592, 47-51.

(44) U.S. Department of Energy (DOE)/NREL/ALLIANCE. Reference Solar Spectral Irradiance: Air Mass 1.5. http://rredc.nrel. gov/solar/spectra/am1.5/ (accessed 2018-02-03).

(45) M’Sabah, B. L.; Boucharef, M.; Warnan, J.; Pellegrin, Y.; Blart, E.; Lucas, B.; Odobel, F.; Bouclé, J. Amplification of light collection in solid-state dye-sensitized solar cells via the antenna effect through supramolecular assembly. Phys. Chem. Chem. Phys. 2015, 17, 99109918.

(46) Virkki, K.; Demir, S.; Lemmetyinen, H.; Tkachenko, N. V. Photoinduced Electron Transfer in CdSe/ZnS Quantum DotFullerene Hybrids. J. Phys. Chem. C 2015, 119, 17561-17572.

(47) Stranius, K.; George, L.; Efimov, A.; Ruoko, T.-P.; Pohjola, J.; Tkachenko, N. V. Photophysical Study of a Self-Assembled DonorAcceptor Two-Layer Film on $\mathrm{TiO}_{2}$. Langmuir 2015, 31, 944-952.

(48) Lehtivuori, H.; Efimov, A.; Lemmetyinen, H.; Tkachenko, N. V. Distributed Decay Kinetics of Charge Separated State in Solid Films. Chem. Phys. Lett. 2007, 437, 238-242. 